\title{
Experiences of black and minority ethnic (BME) students in higher education: Applying self-determination theory to understand the BME attainment gap
}

\author{
Louise Bunce $^{\mathrm{ab}}$, Naomi King ${ }^{\mathrm{ac}}$, Sinitta Saran ${ }^{\mathrm{a}}$, and Nabeela Talib ${ }^{\mathrm{a}}$ \\ aDepartment of Sport, Health Sciences and Social Work, Oxford Brookes University, Jack \\ Straws Lane, Oxford, OX3 OFL, UK \\ bORCID iD: http://orcid.org/0000-0002-8754-9957 \\ 'ORCID iD: http://orcid.org/0000-0002-9887-3031
}

\begin{abstract}
British university students from black and minority ethnic (BME) backgrounds are less likely to achieve a 'good' degree classification than white students, despite taking prior attainment into account. To examine this gap, the current study conducted focus groups with 17 BME students studying health and social care related subjects to understand their experiences of learning and teaching. This was theoretically informed by self-determination theory, which proposes that achieving one's full potential for learning, alongside experience of wellbeing, is supported by environments that help individuals to meet their needs for relatedness, competence, and autonomy. Thematic analysis revealed that BME students encountered many obstacles that inhibited their experience of fulfilment of these three needs, which often undermined their initial desire to achieve their full potential. The findings are discussed in light of how universities can support BME students to achieve their full potential, and in doing so, address the BME attainment gap.
\end{abstract}

\section{Keywords}

BME attainment gap; self-determination theory; diversity; inclusion; psychological needs 
The proportion of black and minority ethnic $(\mathrm{BME})_{1}$ students who enter higher education in the UK is increasing, with $29 \%$ of full-time undergraduate students representing this group in 2015/2016 (Higher Education Funding Council for England [HEFCE] 2017). This is approximately 10 percentage points higher than would be expected based on the proportion of people identifying as BME in the UK population (Cabinet Office 2018). However, there is a significant and inequitable attainment gap between UK-domiciled students from BME groups and white students (Richardson 2008): in 2015/2016, 63\% of BME students achieved a first or upper second class degree (a 'good' degree) 2 in comparison to $78 \%$ of white students (Equality Challenge Unit [ECU] 2017). When this gap is examined for different BME groups, there is some variation; for example, only $52 \%$ of Black African students, but 66\% of Asian students, achieved a 'good' degree in 2015/2016 (ECU 2017). After graduating, subsequent employment rates are also worse for BME students compared to white students (HEFCE 2018), in part because of the job market premium on 'good' degrees (Broecke and Nicholls 2007).

Reasons for the existence of the BME attainment gap are multiple and complex (Smith 2017). Although there are a number of well-known issues that all students may face, including financial pressures, social isolation, and managing the demands of studying with personal and family life (Denovan and Macaskill 2013), BME students face additional challenges. First, they face barriers caused by cultural differences, as well as societal and

\footnotetext{
1 The term BME is used throughout this paper because it is widely recognised to describe patterns of difference on the basis of ethnicity in the UK. BME includes people who identify as Black, Asian, Mixed/Multiple ethnic groups, or Other. We acknowledge that the term is problematic because it disguises diversity within the group.

2 Most UK higher education institutions use a classification system which grades undergraduate degrees into four categories: first class honours (70\% and above, US Grade Point Average 4.0, or Grade A/A+); upper second class honours (60-69\%, approximately US Grade Point Average 3.3-3.7, or Grade B+/A-); lower second class honours (50-59\%, approximately US Grade Point Average 2.7-3, or Grade B-/B), and third class honours (40$49 \%$, approximately US Grade Point Average $2-2.3$, or Grade C-/C+). Many graduate employers and postgraduate courses consider an upper second class degree to be a minimum requirement (Broecke and Nicholls 2007).
} 
institutional racism and discrimination (Cabinet Office 2018; Dhanda 2009; Hillen and Levy 2015). One in six BME students who took part in research by the National Union of Students [NUS] (2011) reported experiencing subtle and covert racism or more explicit bullying. The campus may also be seen as failing to accommodate BME students in terms of food provision and social activities, for example, by not serving halal or kosher food and arranging events that are often centred on alcohol consumption (Hopkins 2011; Sims 2007).

The extent to which the curriculum represents diversity may also be limited: $42 \%$ of BME students surveyed by the NUS (2011) felt that their curriculum was restrictive and did not include issues of diversity, equality, and inclusion. Some students in that research also expressed frustration that their courses were mostly delivered by non-BME staff who were not representative of the student body (see also Bernard et al. 2011, 2014; Dhanda 2009; Osler 1999). Other students and staff may also hold conscious or subconscious negative stereotypes of BME students' academic abilities, and subsequently have lower expectations of them (Bernard et al. 2011; Hopkins 2011; Woolf et al. 2008). Furthermore, BME students who have previously been educated in a different country may have additional barriers to overcome in order to adapt to the UK education system (Dhanda 2009; Shaheen 2016).

Combined, these factors may explain why a dominant theme that emerges from BME students' narratives of their experience at university is that they do not feel they belong in higher education, and experience a sense of 'otherness' or isolation (e.g. Connor et al. 2004; Davies and Garrett 2012; Osler 1999; Read, Archer, and Leathwood, 2003). For example, Stuart, Lido, and Morgan (2011) conducted interviews with students from four different universities in the UK, exploring their experiences of being a university student. From the narratives of BME students emerged issues relating to a sense of alienation and lack of entitlement, for example, students described teachers as underestimating their 
abilities and having low expectations. These experiences resulted in BME students adopting 'coping alone' (504) strategies, which led to fears about not fitting in, a reluctance to ask for help, and even a lack of knowledge about what help was available.

The central theme that emerged from interviews and focus groups with BME students from the University of Chester, UK, was also 'belonging/togetherness' (Davies and Garrett 2012). The predominantly white demographic at this university was noted by students, and contributed to long-term feelings of isolation and lack of belonging. Some of the students also discussed how they actively avoided joining student societies that were linked with individual ethnicities, because they were concerned that this could lead to further ethnic differentiation and segregation. In contrast, six BME students interviewed by Jessop and Williams (2009) at a predominantly white but small university in England, UK, felt a strong sense of belonging on campus, despite at first feeling conspicuous against a 'starkly "white"' student population (100). Students felt that they had integrated easily, and attributed this to the small size of the campus. Despite this, however, they recounted subtle forms of racism that they did not want to explicitly define as racist. One student said: 'I don't think I have [experienced racism] ... um, there are small things, when you wonder, when you think ... ?' (102). They talked about feeling uncomfortable due to awkwardness sometimes felt by white students, which manifested itself in inappropriate humour, questions about origins, or difficulty dealing with texts on racism in class. While this bothered the students, they rationalised racism and attributed it to a lack of diversity on campus and lack of cultural awareness.

Lack of support and belonging has also affected the learning experiences of BME students studying social work (for a review, see Masocha 2015). In a study by Bernard et al. (2014), social work students who were interviewed and took part in focus groups from eight 
universities in England reported a number of issues of marginalisation. The curriculum was perceived as Eurocentric, and implied that European social work interventions were superior to others, thus undermining students' personal and cultural experiences. They also discussed being unhappy about a form of segregation occurring in the classroom: '... white sit with white, black with black. It's very rare to see white with black. Although the course is very diverse' (1939). In addition, they felt tension when classroom discussions came around to beliefs and behaviours that were culturally or racially sensitive, feeling that it might be better to avoid getting involved even when wanting to participate. These issues contributed to what the authors concluded were non-inclusive learning environments that resulted in a lack of 'participatory learning spaces for students from marginalised social groups' (1946).

In another focus group study of undergraduates at an urban post-1992 UK university with a high proportion of BME students (Read, Archer, and Leathwood, 2003), they discussed actively trying to mitigate their position as 'other' by choosing a university that had a high proportion of students 'like them': ‘I didn't want to go to a place where I would be the only speck in, hhh, if you get what I'm saying. So I thought balance was important' (266). Despite this, the theme that ran through the focus groups was not one of belonging but rather isolation; this feeling was not related to the composition of the student body, but one that related to the culture of the institution as disorienting and confusing. Constraints on lecturers' time and availability also led to a feeling of distance between students and their lecturers, and contributed to an overall sense of alienation.

In summary, BME students' sense of belonging is often questioned owing to discourses around them being perceived as 'other' (Read, Archer, and Leathwood, 2003). According to Singh (2011), universities have now accepted that institutional racism, in the form of structural inequalities that arise from teaching, learning, and assessment strategies, 
are in part responsible for some of the negative experiences of BME students and the associated attainment gap, requiring change through partnerships between students and institutions (Broecke and Nicholls 2007; see also Berry and Loke 2011; Richardson 2015; Stevenson 2012). Many universities have invested in projects and set targets to reduce the gap (McDuff et al. 2018; Miller 2016; UUK \& NUS 2019). However, it remains the case that most previous research has been atheoretical and largely descriptive. Furthermore, research is required to examine the experiences of BME students undertaking specific subjects at specific institutions, given that the attainment gap varies by these factors (ECU \& HEA 2008; Richardson 2015). With these issues in mind, the current study focused on the experiences of a sample of BME students who were studying a health and social care related subject at a Post-1992 university in England. It also drew upon self-determination theory (SDT) to provide a theoretical lens though which to understand the experiences of BME students.

SDT is supported by decades of empirical research demonstrating that humans have three psychological needs that underpin our motivation to succeed, our social integration, and ultimately, our wellbeing: relatedness, competence, and autonomy. Relatedness is the need to feel connected to and supported by others, and to have a sense of belonging. As discussed above, most previous research has tended to focus on the extent to which a sense of belonging in general terms is or is not experienced by BME students at university. However, SDT proposes that there are two additional important needs that should be taken into account to provide a complete understanding of our drive to achieve wellbeing and successful fulfilment of our goals. Competence is the need to feel capable and confident to carry out necessary behaviours to reach a goal. It is about self-perceived competence, not objective performance levels; for example, a student who achieves $50 \%$ may experience a sense of competence but a student who achieves $75 \%$ may not, depending on their personal 
circumstances. Autonomy is the need for behaviour to be self-directed and integrated with one's own sense of self, as opposed to being directed or enforced by others. Thus, if a student feels connected to and supported by others (relatedness), capable of achieving their personal goals (competence), and that their behaviour is driven by internal resources rather than by external pressure (autonomy), then they are likely to experience greater wellbeing and achieve their academic potential.

SDT additionally proposes that the extent to which experiencing fulfilment of these three psychological needs is met is substantially affected by external or environmental factors (Deci and Ryan 2000). The use of this theory thus avoids the traditional 'deficit' approach, which views BME students' lower attainment as a consequence of their failure to adjust or adapt, or a lack of ability. The approach inherent in SDT views individuals' disadvantages as the result of external structural and procedural inequalities that undermine their motivation to achieve their full potential (Deci and Ryan 2000). Avoiding a deficit approach is particularly important in view of the phenomenon known as 'internalised racism'. This is when BME people accept racist views by internalising negative attitudes towards themselves, which may include the view that they are not as intelligent as white people (Weissglass 2004). The importance of avoiding a deficit approach is highlighted by other reports of BME student experiences (e.g. NUS 2011), and is implicit in the most recent recommendations for addressing the BME attainment gap, which place the solutions firmly on structural and procedural change in universities (UUK \& NUS 2019).

The aim of this research was to identify the extent to which BME students experienced fulfilment of their three psychological needs during their experiences of learning and teaching in higher education, with an emphasis on the impact of external, environmental factors. This study focused on the psychological needs element of SDT, taking 
a qualitative approach to explore in depth the subtleties and complexities of BME students' reported thoughts, feelings, and experiences (Flick 2018). Focus groups were used to collect data because they enable participants to interact with each other in ways that help them to 'explore and clarify their views in ways that would be less easily accessible in a one to one interview', producing new insights for themselves and for researchers (Kitzinger 1995, 299). They are often used for sensitive topics and for working with minority groups, as participants can provide mutual support in discussing issues and expressing feelings common to their group but perceived as deviating from mainstream culture (Kitzinger 1995). All students on two degree programmes in health and social care related subjects were sent an email inviting those who identified as being from a BME group to take part in a focus group about their experiences of teaching and learning at university. This ensured that the students who participated were genuinely willing to take part and prepared to offer data freely (Shenton 2004).

\section{Method}

\section{Participants}

In total, 17 full-time students from two degree programmes in health and social care related subjects took part. All participants were women, reflecting the fact that women formed the majority of students on the programmes. Their mean age was 32.13 years ( $S D=9.78$, range $=18-50$ years) (two participants preferred not to answer). The participants described themselves as Black African (12), Asian (3), or White and Black Caribbean (2). English was an additional language for 11 participants. Focus Group One comprised three undergraduates 
and one postgraduate. Focus Group Two comprised six undergraduates, and Focus Group Three comprised one undergraduate and six postgraduates.

\section{Procedure}

After gaining ethical approval for the study, email invitations were sent to students who identified as BME in the two health and social care related subjects at one university. Three focus groups were subsequently arranged on campus at convenient times for students. Each focus group was led by a member of staff who also identified as BME and who was independent of the courses. Questions for discussion in the focus groups were developed around the themes of relatedness, competence, and autonomy, as assessed by the Basic Needs Satisfaction Scale (Deci et al. 2001). Example questions were: 'How well do you feel that you fit in with other students on the course?' (relatedness); 'Do you feel that there are any barriers for you to achieve your full potential on the course?' (competence); and 'Do you think that you can be yourself on the course and talk about your own ideas and opinions?' (autonomy). Focus group leaders encouraged students to give concrete examples to illustrate their points. The focus groups lasted approximately $60-90 \mathrm{~min}$. Each student received a $£ 20$ voucher. Focus groups were transcribed verbatim by independent research assistants.

\section{Analysis}

Transcripts were analysed using thematic analysis (TA) and took a hybrid approach, combining inductive (data-driven) and deductive (theory-driven) analysis (Braun and Clarke 2006, 2012; Nowell et al. 2017). Initial codes were drawn from the raw data in a primarily inductive way, concentrating on all aspects of students' reported experiences. Careful analysis of these codes revealed that the impact of external factors was also the focus of 
how BME students spoke about their personal experience, thus confirming the relevance of SDT as an appropriate theoretical lens through which to conduct the analysis. The integration of codes and development of themes were structured according to the needs for relatedness, competence, and autonomy. Due to the orientation of the focus group questions, these three themes captured the large majority of students' statements. Furthermore, the use of SDT also enabled the research to focus on the external factors that influenced their experiences and avoid the deficit approach. The authors were open to data emerging outside the SDT framework and did not use a theoretical lens to override students' stories (Braun and Clarke 2012), but the switch to a deductive approach enabled the study to move beyond descriptive analysis, interpreting the ideas and assumptions that informed the students' explicit articulations (Braun and Clarke 2012).

In the initial familiarisation phase of TA, the first and second authors listened to the audio-recordings, then proceeded with reading, re-reading, and annotating the transcripts. They then coded these annotations and applied labels to meaningful and relevant parts of the data. Following discussion between the first two authors to enable researcher triangulation (Nowell et al. 2017), these codes were listed in a table along with all relevant data extracts. The analysis then shifted to constructing coherent and meaningful patterns from the coded data within the themes of 'relatedness', 'competence', and 'autonomy'. Each of these primary themes comprised two subthemes, 'fulfilment' and 'lack of fulfilment'. The content of these themes and subthemes was reviewed and revised extensively by the first two authors, and subsequently by all four authors, and checked to ensure that they had 'internal homogeneity' (meaningful data cohesion within each theme) and 'external homogeneity' (clear differences between the themes) (Patton 1990). To ensure that the findings accurately represented the views of participants, the results section 
plus a request for feedback were sent to all students who had taken part (Nowell et al. 2017). Minor changes were subsequently made in line with student feedback.

\section{Results}

The analysis is presented in three sections that consider the extent to which students felt that external factors in the learning and teaching environment impacted on the extent to which their needs for relatedness, competence, and autonomy at university were unfulfilled or fulfilled.

\section{Relatedness}

Lack of fulfilment of the need for relatedness

In all three focus groups, students spoke extensively about how a lack of relatedness affected their learning experiences and outcomes, as well as their overall wellbeing. Many reported feeling excluded, frustrated, and distressed during their degree courses, and linked this directly to their BME status:

In my class ... when I first started, it was like, I almost left. [...] [Crying] I wasn't the only black person in the class, but I was the only ... [...] [There's another black student], but she's now British, she was born here, [crying] she's got a British accent, I have an African accent. [...] I didn't have anyone to turn to. [...] I was isolated, it was like no one wanted to be with me. (P2)

The students attributed lack of relatedness partly to low ethnic diversity on campus, reporting how the large majority of staff and students were non-BME and did not understand the cultures and backgrounds that BME students came from, or the challenges that they faced: 
In the whole [accommodation] block, I'm the only black person. [...] There's no-one, like, I can like talk to, and have those type of conversations [...] [about] the culture that l've been brought up in. (P3)

They recounted many incidents of direct or indirect racism, both in the learning environment and work placements. This was 'such a taboo subject' (P1) that many students found it difficult to report and challenge such incidents. They felt that BME people were frequently stereotyped as having lower intellectual ability, more mental health problems, or as being 'bad people' and 'criminals' (P1), and that these stereotypes were sometimes reinforced by course materials:

We are in a lecture, and we have group work, someone put on their references, that they read in the research, that ethnic minorities were higher in mental health issues, compared to [...] British people. [...] [Actually] it said black people. It didn't even say minority people. [...] It's things like this that build stigma in class. (P8)

The students reported how they were often ignored or avoided by some of their non-BME student peers, and excluded from groups within and outside of class:

I think because we are minority group, [...] it's like others won't talk to you because of the way you look, or the place where you're coming from. (P10)

I had this horrible experience from the beginning, because there was a white student guide there [...] and I looked at him, and stood right in front of him, and I was like, you know, 'Where do I go? Help me!' And he just looked me up and down, and there was a white girl walked in behind me, and he was like, 'Oh hi, can I help you there?' (P15)

They described how they often perceived being judged by non-BME students and staff in terms of their skin colour and accents: 
I know that the first thing that someone's going to see me as is a 'black woman'. [...]

I'm more than that [...] but you can't change people and their perception of you. (P3)

\section{Fulfilment of the need for relatedness}

In all focus groups, most students spoke about how they experienced relatedness with certain members of staff and student peers. Many talked about belonging to a group of BME friends, which offered a powerful sense of support:

I'm glad I'm not the only, like, black person in our class. [...] I feel really comfortable with you guys. [...] I literally just loved the conversation me, you, and [classmate] had. It was just so honest. And I felt like we didn't have to [...] be careful, or anything, we just understood each other. [...] I felt so, like, comfortable, and I felt so happy. (P3)

They also emphasised, however, that much more should be done to foster an inclusive environment which enabled BME and non-BME students to integrate. Although they appreciated the fact that the university ran regular events and activities for BME students, these were felt to be double-edged as they made BME students feel separate, and left nonBME students with a lack of understanding:

[There] are activities for BMEs [...] but I think that if my class sat in here and had their opinion of what I'm sharing today, it is helpful to them, that's where the changes need to be, in terms of integration. Rather than putting me out of that group and saying it separately. [...] You can't integrate one party and the other party is absent. (P7)

Some felt that the majority of their non-BME student peers were generally friendly and supportive: 
In terms of fitting in [...] I can sit and engage with anyone, I can have a conversation with anyone to be honest, and I think once we get talking, they're quite accommodating. [...] In terms of the class in general, I've got no issues. (P8) Many students emphasised that they gained a sense of secure connection with a few nonBME lecturers who were warm, caring, and open-minded, but they perceived these lecturers as the minority:

[Lecturer A] understands [our concerns], she gets it, she could relate to it. And I think we need people like that, where we think we'll feel safe, to go and talk to. (P13)

\section{Competence}

Lack of fulfilment of the need for competence

In all focus groups, many students explained that they felt a lack of competence in the higher education environment. Some reported that this was partly a result of cultural differences between the country in which they were raised and the UK, as they received little support for adapting to the UK higher education system:

I've actually lost a bit of my confidence. [...] I found I didn't know as much as I thought I knew. [...] Some of the stuff I grew up with is not what's reflected here. [...] My upbringing and how things are done over here, it's quite different. [...] It was kind of like, I had to learn [to adapt to the UK higher education system] by myself. (P2) Many students were disappointed with their grades and were left feeling they had not achieved their full potential. They described putting a lot of effort into their work, but felt that this was not rewarded by the marks they received. For some students, this ultimately had a negative impact on their motivation for studying: 
Yeah, I feel that I put in a lot, that the grades that I got, they didn't reflect on the work. (P12)

[Now] I just want to pass, I just want to get it scraped through and go, but, sitting here and reflecting, the truth about it is, if we were given the opportunity to be at our best, most of us would have excelled. (P16)

They perceived low grades as particularly demoralising because they felt that they had to be 'twice as good' when competing with non-BME people for employment. This 'twice as good rule' (P1) was drilled into them by the barriers that they and their families faced:

If you are of a minority, in order for you to achieve something that a white person achieves, you have to be twice as good, yeah, you can't just be on the same level as a white person. (P2)

Many discussed how they did not feel sufficiently supported to reach the high academic standards they wanted to achieve:

I, myself, am not happy with [just] a pass. If I get a 50, I'm very annoyed, I'm not happy with that, because I put work into that. [...] We're people of pride, and we want to do well. [...] It's not just the fact that we want to be, you know, mediocre we want to be above average. But here, I feel that it has not been facilitated, it has not been supported, by everybody. (P14)

In addition, some felt that their assessments may have been misunderstood as a result of cultural differences between themselves and non-BME lecturers:

Say we are writing essays that relate to our cultural backgrounds, or our identity ... they may not necessarily understand and have a bias about it. [...] We can be very honest and candid, in terms of bringing our life experiences into it, but, they may not 
necessarily understand it, and [...] I'm not saying they view it as wrong, but, because they don't understand it, they may mark it down. (P3)

Another barrier to experiencing fulfilment of the need for competence was the perception that BME students were consciously or unconsciously perceived as less capable by both academics and their student peers, for reasons including their non-standard accents and the entrenched, discriminatory stereotypes of BME people:

For me, $[\ldots][\mathrm{my}]$ accent and all that, it really does make me feel like [...] we've sort of been written off before we've even been given a chance. [...] [With one lecturer] we are assured in the lesson that BME student groups, over the years, have come out statistically ... that they don't perform very well. And this is, like, in class. (P8)

There are some [academics] who are like ... I mean I said earlier, you've already been judged [...] and some people doubt us because we are BMEs, like we don't have that deep ability, like even when you say something in class, you feel it's being, like, scrutinised. (P5)

Several students gave examples of how they felt they were being ignored or overlooked by lecturers, which eroded their self-confidence:

I just feel that certain, like, lecturers ... treat you differently. I mean you could say something and they would just not really acknowledge what you're saying. [...] There's one or two [lecturers] that do make me feel uncomfortable. (P1)

\section{Fulfilment of the need for competence}

In two of the focus groups, most students described how their need for competence had been fulfilled in certain ways. Several reported that some lecturers were very supportive 
and gave positive feedback. This boosted the students' confidence, helping them to speak out in class, learn from each other, and ultimately get higher grades:

Some teachers will be like, 'Yeah, well done, that's really good, that's a good point', and then somebody else will get involved and, you know, then you [...] start having, like, a debate. [...] People should be able to all talk together and learn from each other. [...] We've actually all done better in [Lecturer B's] lessons. (P1)

Other students explained how they felt that their courses had made them feel competent on a broader level, improving their general confidence by helping them to gain skills that were useful in higher education and beyond:

So far [on the course] a lot of things [...] have changed. [...] Like my thinking. [...] It's changed my thinking orientation about parts of my life, you know. And I reflect every day. I used to, but the way I do it now is a very different level. (P7)

I'd say this course, at the moment, it's given me ... a different perspective. l'll come in and I'll hear somebody's opinion, so that has helped me. (P9)

\section{Autonomy}

Lack of fulfilment of the need for autonomy

In all focus groups, students spoke at length about how they felt they could not be themselves in the higher education environment. They felt pressurised to behave in ways that complied with non-BME norms on campus and in placements:

I feel like an imposter. [...] [With lecturers] I put on an act ... my accent changes, my voice changes, and I'll pretend that I am a clever person. [...] If I, you know, put on my real accent and if I talked like where I come from, I probably wouldn't be that well liked there. [...] I feel a bit fake. (P15) 
I know that when I'm out in public [...] I get a bit like ... like it's Queen's English. [...]

We have to put on the acceptable front, you know, the package ... to prove yourself to fit into white society. [...] You can't be yourself. (P14)

Many reported that this was reinforced by course materials, which they considered restrictive and lacking relevance for BME students:

If it was up to me, the content would be very different. [...] There's just so many holes within that content that we're taught. [...] I feel like diversity is like this little bit of salt that they put right at the end, that's just like a little garnish. [...] There's just hardly anything on ... black and ethnic minorities. (P4)

Several students indicated that they felt uncomfortable about expressing their own ideas in class:

I think I have an idea, and I'll put it across, but it's ... you're immediately put on the spot and you're like, oh gosh, or you're made to feel like it's a stupid question. You shouldn't be thinking that way! I feel, oh you know, l'd better keep quiet and not contribute. (P9)

Some students reported that they tried to challenge this barrier by raising issues of ethnicity in class or making formal complaints about discrimination, but they emphasised that this was stressful, tiring, and demoralising. While some students felt 'fired up' to challenge the restrictive curriculum, others found it to be highly demotivating:

I feel like, I have been now labelled as the kid in the class, the only kid in the class, who will talk about race, and ethnicity and all those things. [...] In that I felt isolated and alone. (P4)

We came with high expectations, everybody wants ... well it's human nature to want to do well. [...] But everything has been such a struggle, and we're just like, we can't 
be bothered now. [...] I've gone through life, and I have had to shout and fight and challenge and raise and re-raise and re-challenge [...] and that is bloody tiring. I'm knackered, I am tired, I am fed up. (P14)

\section{Fulfilment of the need for autonomy}

In all focus groups, some students spoke about how a minority of lecturers facilitated autonomy through teaching about diversity and encouraging students to explore their own identities. They described this as cathartic and liberating:

I really enjoyed one of our sessions, we were talking about ethnicity and identity, and I really enjoyed that lecture, because, I felt just, like, so ... liberated, I felt, like, so comfortable talking about, like real things that could affect me. [...] These are things that need to be spoken about. (P3)

In one focus group, all students emphasised how the course as a whole helped them to understand themselves in better ways through becoming open-minded critical thinkers. They felt this enabled them to take more control of their thoughts and actions:

It has made me think more critically about what I say. [...] It's thinking like that, that makes you a lot more aware. It's also allowed me to think of other daily parts of my life as well, it's very helpful, so if I'm in a little bit of trouble or stress [...] I'll just think of it critically, be like, ok, l'll look at it from this angle, so it's become very helpful. (P6)

\section{Discussion}

The existence of an attainment gap in degree outcomes between black and white students in higher education in the UK requires urgent attention to address institutional causes of 
inequality. This is a highly topical issue. The UK government recently launched measures to drive change in tackling inequalities between ethnic groups, including holding universities to account through their Access and Participation plans, and putting pressure on university league tables to include progress in tackling access and attainment disparities (Diversity UK 2019). However, there is a significant lack of in-depth, theory-driven research to help understand the experiences of BME students, which can contribute to recognising potential causes and developing solutions to address the attainment gap.

The current study explored BME students' perceptions of the learning and teaching environment and its impact on the extent to which they experienced fulfilment of the psychological needs for relatedness, competence, and autonomy. Most students who took part in the focus groups spoke extensively and in depth about how these needs had generally not been fulfilled, which subsequently had a negative impact on their motivation to achieve their full potential and general wellbeing. However, some students also discussed how their needs for relatedness, competence, and autonomy had occasionally been met, for example, when being taught by a particular lecturer or engaging with BME peers.

On a surface level, the findings reflect the experiences of many BME students that have previously been reported in an atheoretical way in previous research. However, the application of SDT in the current study provided richer insight into their experiences of learning and teaching that impact on their fulfilment of the needs for relatedness, competence, and autonomy. The discussion will now consider the results regarding each of the three needs in turn, and present implications for learning and teaching practice.

Lack of fulfilment of the need for relatedness was critical in undermining BME students' motivation for academic success and wellbeing, and consequently had a negative influence on their sense of autonomy and competence. Research applying SDT to education 
often describes students' experience of relatedness in relatively straightforward terms, such as 'feeling that the teacher genuinely likes, respects, and values him or her' as opposed to feeling 'disconnected or rejected by teachers' (Niemiec and Ryan 2009, 139-140). The current study exposed a more complex situation experienced by BME students, in which they described a lack of relatedness not only with non-BME lecturers, but with non-BME peers inside and outside the classroom, and with non-BME staff and service users on work placements. They attributed this to factors including low ethnic diversity on campus, and non-BME people judging them in terms of their skin colour or accent and assigning them to a 'minority group'. In line with other studies (e.g. Bernard et al. 2011, 2014; Jessop and Williams 2009), students reported incidents of direct and indirect racism, often linked to discriminatory stereotypes that were embedded in UK society. They thought they were often perceived as inferior to non-BME students, a view sometimes reiterated by course materials and endorsed by non-BME lecturers who did not 'understand' their backgrounds or the challenges that they faced. These lecturers were not seen as using teaching styles that discouraged relatedness in general; rather, they seemed to treat BME students differently and with less empathy. The students also reported being ignored or avoided by their non-BME peers, which led to a painful sense of isolation and lack of belonging. For many, this was not a temporary occurrence but a continuous issue that seemed to permeate most aspects of their higher education experiences. It was felt to diminish their overall wellbeing, evoking a range of negative emotions including discomfort, distress, frustration, and anger.

The need for competence appeared largely unfulfilled for students in the current study, many of whom described being disappointed with their grades. Despite entering the course with high aspirations and putting much effort into their work, students felt that they 
were not given the opportunity to achieve their full potential and reach their personal goals. Compared to their peers, they felt that the teaching and learning environment stifled their potential to 'excel'. For some international BME students, this was linked to lack of support for adapting to the UK higher education system, an issue highlighted in previous research (e.g. Hillen and Levy 2015; Shaheen 2016). There was also a widespread sense that lecturers might be marking their assignments down, due to factors including lack of understanding of their cultural backgrounds and perspectives, and stereotypical perceptions of BME people lacking intellectual ability. This issue was raised in the NUS report (2011), which revealed that fair assessment and transparent marking procedures were a key point of concern for BME students. In both the current study and the NUS report, such prejudice was additionally perceived to manifest in the classroom, diminishing BME students' self-confidence when they felt their views were being ignored and dismissed.

In terms of autonomy, many BME students felt strongly that this need was unfulfilled. Rather than simply encountering controlling, prescriptive teaching styles in the classroom (Deci et al. 1991; Niemiec and Ryan 2009), these students described how the higher education environment had a negative impact on their sense of identity. Several spoke explicitly about how they could not be themselves, but felt pressured into complying with dominant social norms to 'fit into white society'. This led to internal conflict, and, for some, involved changing their accents and feeling 'a bit fake'; one student referred to 'imposter syndrome', a doubting of one's accomplishments and feelings of fraudulence because one does not attribute success to one's own abilities (Clance and Imes 1978). This has been linked to diminished self-confidence and self-esteem, along with higher stress and anxiety (Parkman 2016). Many students thought that their autonomy was restricted by the narrow curriculum, and felt unable to express their own views because their perspectives 
were seen as irrelevant. Students appeared divided in their responses to this autonomyrestrictive culture. Some students took a passionate, proactive approach and were strongly motivated to raise issues of ethnicity and make complaints about discrimination to maintain their own values and sense of identity. However, their attempts to challenge the system were tiring and demoralising. On the other hand, some students felt that overcoming the system was impossible, and they became highly demotivated and disengaged. They shifted their focus to doing the minimum amount of work necessary to achieve their degree.

\section{Implications}

SDT has broadened our understanding of the experiences of BME students in higher education, and is of significance for academics and institutions whose aim is to support students' natural tendency for intrinsic motivation (Ryan and Deci 2000). We now consider ways that our findings could be utilised in practice to improve BME students' experience, which may ultimately address the BME attainment gap.

First, it should be noted that non-BME staff may lack awareness and understanding of issues affecting BME students, and feel uncomfortable in trying to address them. Potential reasons for this have been found to include a lack of belief among staff that their own institutions are racist; a perception that racism is an external, societal problem rather than an internal, institutional one; and unwillingness to discuss these issues with BME students for fear of being politically incorrect and 'saying the wrong thing' (Stevenson 2012, 8). In addition, some staff may attribute the achievement gap between BME and non-BME students to the 'deficit model', a view that the problem lies with the students or their backgrounds rather than institutional factors (Stevenson 2012). It will be crucial, therefore, for institutions to provide relevant training on equality, diversity, and inclusion, and to 
ensure that staff acknowledge and internalise the importance of challenging racism and discrimination. This will enable interventions to be carried out in a constructive and meaningful way, as opposed to being perceived as externally imposed 'tick-box' exercises.

Fostering relatedness could be strongly supported by lecturers being empathic, approachable, and open-minded. Making personal contact with students and treating them as individuals could help to build rapport and establish relationships of trust. Students in the current study emphasised the value of connecting with staff who were warm, caring, nonjudgemental, and made them 'feel safe'; if all staff members adopted such approaches, it could play a significant role in removing the 'taboo' barrier of reporting racist incidents. BME students' sense of safety could also be improved by universities providing support at all levels for effectively tackling racism and discrimination. More broadly, students highlighted the need to gain more BME representation in the staff body, which may be supported by universities gaining the Race Equality Charter Mark and offering training designed to support BME staff in applying for promotion.

Relatedness among BME students themselves could be facilitated by establishing support systems such as peer mentoring schemes, and holding focus groups to discuss and raise issues. Students taking part in the current study described how they 'understood each other', felt 'really comfortable', and even suggested that they meet regularly to 'empower' each other. It would be essential to avoid homogenising BME students and distancing them from their non-BME peers, however. Lecturers could play a vital role in developing an inclusive community among students that is appreciative and respectful of cultural differences, and facilitates integrative relationship building.

In terms of supporting competence among BME students, lecturers need to be conscious about giving supportive feedback, for example, by acknowledging a contribution 
made by a BME student, or by showing further curiosity about an issue raised by a BME student. Students in the current study felt that these small but significant acknowledgements raised their confidence and helped them to feel safe speaking out in class. Competence for BME students unfamiliar with the UK higher education system also needs to be enhanced by the provision of opportunities to attend meetings, workshops, and seminars designed to help them navigate higher education.

Students' autonomy can be supported by minimising 'any sense of coercion in the classroom' and maximising their 'perceptions of having a voice and choice' in their academic activities (Niemiec and Ryan 2009, 139). In the focus groups, many students reported that they could not be themselves on campus, explaining that they sometimes felt that they had to change their accents and voices to 'fit into white society'. The way that a minority of lecturers encouraged students to explore their own identities was perceived as extremely cathartic and liberating. Such kinds of teaching could be encouraged across all courses, and extended by programmes designed to internationalise, diversify, and decolonise the curriculum (NUS 2011). This has already achieved much media attention with campaigns such as 'Why is my curriculum white?', started by students at UCL (UCL 2014). The aims of such campaigns are both to raise awareness of the curriculums that do not recognise scholarship from other cultures and people of other races, as well as to initiate a change so that curriculums become more diverse (Hussain 2015).

\section{Conclusion}

Exploring the extent to which BME students gain fulfilment of the needs for relatedness, competence, and autonomy has provided a much deeper and theoretically based account of their experiences of teaching and learning in higher education than previous research. 
Higher education has the potential to offer all students life-changing and transformative experiences, but for this to become the norm for BME students, universities will have to undergo a significant transformation. By addressing institutional causes of a lack of fulfilment of the needs for relatedness, competence, and autonomy, universities can make substantial gains towards reducing the inequitable BME attainment gap.

\section{Acknowledgements}

We would like to thank all of the students who took part in the focus groups for being so candid with us, and Mariama Sheriff, Yue Ang, and David SSebiriko who conducted the focus groups.

\section{References}

Bernard, C., Fairtlough, A., Fletcher, J. \& Ahmet, A. 2011. Diversity and progression among social work students in England. London: Goldsmiths University. Accessed from https://research.gold.ac.uk/6326/2/DH Final Report 18 July 2011.pdf

Bernard, C., Fairtlough, A., Fletcher, J. \& and Ahmet, A. 2014. “A Qualitative Study of Marginalised Social Work Students' Views of Social Work Education and Learning." The British Journal of Social Work 44(7): 1934-1949.

Berry, J. \& Loke, G. 2011. Improving the Degree Attainment of Black and Minority Ethnic Students. Accessed from http://www.ecu.ac.uk/wpcontent/uploads/external/improving-degree-attainment-bme.pdf

Braun, V. \& Clarke, V. 2006. "Using thematic analysis in psychology." Qualitative Research in Psychology 3(2): 77-101. 
Braun, V. \& Clarke, V. 2012. Thematic analysis. In H. Cooper, P. M. Camic, D. L. Long, A. T. Panter, D. Rindskopf, \& K. J. Sher (Eds.), APA Handbook of Research Methods in Psychology, Vol. 2 (pp. 57-71). Washington, DC: American Psychological Association.

Broecke, S. \& Nicholls, T. 2007. Ethnicity and Degree Attainment (Research Report RW92). London: Department for Education and Skills. Accessed from www.dcsf.gov.uk/research/data/uploadfiles/RW92.pdf

Cabinet Office. 2018. Race Disparity Audit. Accessed from https://www.gov.uk/government/publications/race-disparity-audit

Clance, P. R. \& Imes, S. A. 1978. "The impostor phenomenon in high achieving women: Dynamics and therapeutic intervention." Psychotherapy: Theory, Research, and Practice 15(3): 241-247.

Connor, H., Tyres, C., Modood, T. \& Hillage, J. 2004. Why the Difference? A closer look at higher education minority ethnic students and graduates. Research Report No. 552. London: DfES.

Davies, C. \& Garrett, M. 2012. The BME student experience at a small northern university: An examination of the experiences of minority ethnic students undertaking undergraduate study within a small northern university. Compass: The Journal of Learning and Teaching at the University of Greenwich 5: 1-10.

Deci, E. L. \& Ryan, R. M., 2000. "The "what" and "why" of goal pursuits: Human needs and the self-determination of behavior." Psychological Inquiry 11(4): 227-268.

Deci, E. L., Ryan, R. M., Gagné, M., Leone, D. R., Usunov, J. \& Kornazheva, B. P. 2001. “Need satisfaction, motivation, and well-being in the work organizations of a former eastern bloc country: A cross-cultural study of self-determination." Personality and Social Psychology Bulletin 27: 930-942. 
Deci, E. L., Vallerand, R. J., Pelletier, L. G. \& Ryan, R. M. 1991. “Motivation and education: The self-determination perspective." Educational Psychologist 26: 325-346.

Denovan, A. \& Macaskill, A. 2013. "An interpretative phenomenological analysis of stress and coping in first year undergraduates." British Educational Research Journal 39: $1002-1024$.

Dhanda, M. 2009. Understanding Disparities in Student Attainment: Black and Minority Ethnic Students' Experience. Accessed from http://www2.wlv.ac.uk/equalopps/mdsummary.pdf

Diversity UK. 2019. Universities must do more to tackle ethnic disparity. Accessed from https://diversityuk.org/universities-must-do-more-to-tackle-ethnic-disparity/ Equality Challenge Unit. 2017. Equality in Higher Education: Statistical Report. Accessed from https://www.ecu.ac.uk/publications/equality-in-higher-education-statisticalreport-2017/

Equality Challenge Unit \& Higher Education Academy. 2008. ECU Ethnicity, Gender and Degree Attainment Project Final Report, York: The Higher Education Academy. Accessed from http://www.ecu.ac.uk/wp-content/uploads/external/ethnicitygender-and-degree-attainment-project-final-report.doc

Flick, U. 2018. An Introduction to Qualitative Research (6th ed.). London: Sage.

Higher Education Funding Council for England. 2017. Student Characteristics. Accessed from http://www.hefce.ac.uk/analysis/HEinEngland/students/

Higher Education Funding Council for England. 2018. Differences in Student Outcomes: The Effect of Student Characteristics. Accessed from http://www.hefce.ac.uk/pubs/year/2018/201805/ Hillen, P. \& Levy, S. 2015. “Framing the experiences of BME social work students within a 
narrative of Educating for a Culturally Diverse Workforce." Social Work Education 34: 785-798.

Hopkins, P. 2011. "Towards critical geographies of the university campus: understanding the contested experiences of Muslim students." Transactions of the Institute of British Geographers 36: 157-169.

Hussain, N. 2015, March 11. Why is my curriculum white? Accessed from https://www.nus.org.uk/en/news/why-is-my-curriculum-white/

Jessop, T. \& Williams, A. 2009. "Equivocal tales about identity, racism and the curriculum." Teaching in Higher Education 14(1): 95-106.

Kitzinger, J. 1995. "Qualitative research: Introducing focus groups.” BMJ, 311: 299-302. Masocha, S. 2015. “Reframing black social work students' experiences of teaching and learning." Social Work Education 34(6): 636-649.

McDuff, N., Tatam, J., Beacock, O. \& Ross, F. 2018. “Closing the attainment gap for students from black and minority ethnic backgrounds through institutional change." Widening Participation and Lifelong Learning 20: 79-101.

Miller, M. 2016. The Ethnicity Attainment Gap: Literature Review. Accessed from https://www.sheffield.ac.uk/polopoly fs/1.661523!/file/BME Attainment Gap Liter ature Review EXTERNAL - Miriam Miller.pdf

Niemiec, C. P. \& Ryan, R. M. 2009. “Autonomy, competence, and relatedness in the classroom: Applying self-determination theory to educational practice." School Field 7: 133-144.

Nowell, L. S., Norris, J. M., White, D. E. \& Moules, N. J. 2017. “Thematic analysis: Striving to meet the trustworthiness criteria." International Journal of Qualitative Methods 16: $1-13$. 
NUS. 2011. Race for Equality: A Report on the Experiences of Black Students in Further and Higher Education. London: National Union of Students.

Osler, A. 1999. "The educational experiences and career aspirations of black and ethnic minority undergraduates." Race, Ethnicity and Education 2: 39-58.

Parkman, A. 2016. "The imposter phenomenon in higher education: Incidence and impact." Journal of Higher Education Theory and Practice 16: 51-60.

Patton, M. Q. 1990. Qualitative Evaluation and Research Methods. Newbury Park, CA: Sage.

Read, B., Archer, L. \& Leathwood, C. 2003. “Challenging cultures? Student conceptions of 'belonging' and 'isolation' at a post-1992 university." Studies in Higher Education 28: 261-277.

Richardson, J. T. E. 2008. "The attainment of ethnic minority students in UK higher Education." Studies in Higher Education 33: 33-48.

Richardson, J. T. E. 2015. "The under-attainment of ethnic minority students in UK higher education: what we know and what we don't know." Journal of Further and Higher Education 39: 278-291.

Ryan, R. M. \& Deci, E. L. 2000. "Intrinsic and extrinsic motivations: Classic definitions and new directions." Contemporary Educational Psychology 25: 54-67.

Shaheen, N. 2016. “International students' critical thinking-related problem areas: UK university teachers' perspectives." Journal of Research in International Education 15: $18-31$.

Shenton, A. K. 2004. "Strategies for ensuring trustworthiness in qualitative research projects." Education for Information 22(2): 63-75.

Sims, J. M. 2007. "Not enough understanding? Student experiences of diversity in UK universities." London: Runnymede Trust. 
Singh, G., 2011. Black and Minority Ethnic (BME) Students' Participation in Higher Education: Improving Retention and Success. Accessed from https://www.heacademy.ac.uk/knowledge-hub/black-and-minority-ethnic-bmestudents-participation-higher-education-improving

Smith, S. 2017. "Exploring the Black and Minority Ethnic (BME) student attainment gap: what did it tell us? Actions to address home BME undergraduate students' degree attainment." Journal of Perspectives in Applied Academic Practice, 5: 48-57.

Stevenson, J. 2012. Black and Minority Ethnic Student Degree Retention and Attainment. Accessed from https://www.heacademy.ac.uk/sites/default/files/bme summit final report.pd Stuart, M., Lido, C. \& Morgan, J. 2011. “Personal stories: how students' social and cultural life histories interact with the field of higher education." International Journal of Lifelong Education 30(4): 489-508.

UCL. 2014. Why is My Curriculum White? Accessed from http://www.dtmh.ucl.ac.uk/videos/curriculum-white/

UUK \& NUS. 2019. Black, Asian and Minority Ethnic Student Attainment at UK Universities: \#closing the gap. Accessed from https://www.universitiesuk.ac.uk/policy-and-analysis/reports/Documents/2019/ $\underline{\text { bame-student-attainment-uk-universities-closing-the-gap.pdf }}$

Weissglass, J. 2004. "Racism and the achievement gap." Education Week, 20: 49-72.

Woolf, K., Cave, J., Greenhalgh, T. \& Dacre, J. 2008. “Ethnic stereotypes and the under achievement of UK medical students from ethnic minorities: Qualitative study." British Medical Journal, 337:611-615. doi:10.1136/bmj.a1220. 